Classification

Physics Abstracts

$61.16 \mathrm{P}-98.20-73.40 \mathrm{M}-81.60 \mathrm{C}$

\title{
Structure of $\mathrm{Si}(111)$ surfaces etched in $40 \% \mathrm{NH}_{4} \mathrm{~F}$ : Influence of the doping
}

\author{
J.R. Roche $\left({ }^{1}\right)$, M. Ramonda $\left({ }^{1}\right)$, F. Thibaudau $\left({ }^{1}\right), \operatorname{Ph} . \operatorname{Dumas}\left({ }^{1}\right), \operatorname{Ph} . \operatorname{Mathiez}\left({ }^{1}\right)$, F. Salvan $\left({ }^{1}\right)$ \\ and $\mathrm{P}$. Allongue $\left({ }^{2}\right)^{*}$ \\ ( $\left.{ }^{1}\right)$ Groupe de Physique des Etats Condensés, (URA CNRS 783), Faculté des Sciences de Luminy, \\ 13288 Marseille Cedex 9, France \\ ( $\left.{ }^{2}\right)$ Laboratoire de Physique des Liquides et Electrochimie, UPR 15 CNRS, Université P. \& M. Curie, \\ 4 Place Jussieu, 75005 Paris, France
}

(Received July 4; accepted December 16, 1994)

Résumé. - La topographie de surface de plaquettes de $\mathrm{Si}(111)$ de type $\mathrm{n}$ et $\mathrm{p}^{+}$, orientées précisément, est étudiée par STM (dans le vide) et AFM (à l'air ambiant) après attaque "chimique" dans une solution de $\mathrm{NH}_{4} \mathrm{~F}$ à $40 \%$. Il apparaît que le substrat de type n donne une surface plane à l'échelle atomique, et que la surface du substrat $\mathrm{p}^{+}$est toujours rugueuse. On montre que ces observations résultent d'une augmentation de la composante électrochimique de la dissolution à la surface de type $\mathrm{p}^{+}$.

\begin{abstract}
The morphology of precisely oriented $\mathrm{n}$ and $\mathrm{p}^{+}$type $\mathrm{Si}(111)$ hydrogenated surfaces has been studied by UHV-STM and AFM at ambient after "chemical" etching in $40 \% \mathrm{NH}_{4} \mathrm{~F}$. Whereas atomically flat surfaces are obtained with the n-type samples, the surface of $\mathrm{p}^{+}$substrates is rough. It is shown that these observations stem from a variation of the partition between the chemical (anisotropic) and the electrochemical (isotropic) components of the etching reaction. This is the uptake of the latter reaction path at the $\mathrm{p}^{+}$-type specimen which explains the surface roughening in this case.
\end{abstract}

\section{Introduction.}

The preparation of semiconductor surfaces is a critical step before patterning in microelectronic technology. Atomically flat with controlled chemistry surfaces are being necessary to increase integration. ULSI (ultra large scale integration) circuits require for instance gate oxide films with thicknesses in the nanometer range. Various preparation techniques have been developed so far. They generally consist in a series of oxidation steps followed by oxide stripping and a final etch in solutions containing $\mathrm{HF}, \mathrm{NH}_{4} \mathrm{~F}, \mathrm{NH}_{4} \mathrm{OH}$ and $\mathrm{NaOH}$. Although the Si surface remains always

* to whom correspondence should be addressed. 
terminated by a monolayer of hydrogen atoms [1-4], such wet treatments are able to produce surfaces with different morphologies, as it has been studied by ex-situ (in the UHV) [5] or in-situ (i.e. in the solution) STM imaging [6-10] or by studying the IR absorption stretching modes of Si hydride species at the surface [11-12]. The $\mathrm{H}$-termination, as well as the $\mathrm{pH}$ dependence of the atomic structure of $\mathrm{n}-\mathrm{Si}(111)$ surfaces, has been recently explained by reaction models describing the process at the molecular level $[9,13-14]$.

Since the work of Chabal and co-workers [12], it has become very topical to prepare ideal atomically flat $\mathrm{Si}(111)$ surfaces by etching in $40 \% \mathrm{NH}_{4} \mathrm{~F}$. The role of the surface miscut has been also studied in details [15]. Nonetheless, no report has been published concerning the influence of the doping of substrates. This paper presents scanning probe microscopy images showing that the atomic structure of precisely oriented $\mathrm{Si}(111)$ surfaces depends on the type of conduction of wafers $\left(\mathrm{n}\right.$ or $\left.\mathrm{p}^{+}\right)$. As reported by others, atomically flat surfaces are indeed obtainable with $\mathrm{n}$ $\mathrm{Si}(111)$ but not with $\mathrm{p}^{+}$samples which has never been explained. These findings are discussed within the framework of previously published reaction mechanisms and energy diagrams of the interface $\mathrm{Si}(111) / \mathrm{NH}_{4} \mathrm{~F}$ solution.

\section{Experimental.}

Samples were cut from precisely oriented Si(111) wafers (Virginia Semiconductors, U.S.A.). They were first degreased in organic solvents and cleaned according to the RCA treatment [16] including a first oxidation step in a mixture $\left(\mathrm{NH}_{4} \mathrm{OH} 28 \%, \mathrm{H}_{2} \mathrm{O}_{2} 30 \%, \mathrm{H}_{2} \mathrm{O}\right)$ (volume proportions respectively $1,1,4)$, followed by a succession of oxidation in a mixture $\left(\mathrm{HCl} 36 \%, \mathrm{H}_{2} \mathrm{O}_{2} 30 \%, \mathrm{H}_{2} \mathrm{O}\right)$ $(1,1,4)$ and oxide stripping in HF. Between each of these steps samples were rinsed with $18 \mathrm{M} \Omega . \mathrm{cm}$ deionized water. After the last oxidation, the surface was finally etched in $40 \% \mathrm{NH}_{4} \mathrm{~F}(\mathrm{pH} 8)$.

Experiments have been conducted with $\mathrm{n}$ type $\left(\rho \sim 5 \times 10^{-2} \Omega . \mathrm{cm}\right.$, As dopant $)$ and $\mathrm{p}^{+}$type $(5 \times$ $10^{-3} \Omega . c m, B$ dopant) samples. Surfaces were characterized by XPS to check contamination by O, $\mathrm{C}$ and F. The surface topography was studied by AFM at ambient or UHV-STM after introduction of the sample in the UHV chamber via an air-lock system. The surface roughness has been also investigated by determining the rms height profile [17].

\section{Results.}

Figure 1 presents AFM images showing the evolution of the surface of $\mathrm{p}^{+}-\mathrm{Si}(111)$ with increasing etching times in $40 \% \mathrm{NH}_{4} \mathrm{~F}$. Even the initial $\mathrm{H}$-terminated substrate is not ideally flat. The roughness increases with time and it was found that it presented no preferential directions. The time dependence of the rms is shown in figure 2. Figure 3 is a typical UHV-STM image of the surface of the low doped n-type $\mathrm{Si}(111)$ after a 4 min of etching. Eight atomic layers are exposed in this image. The directionality of the attack is accounted by the triangular shape of etch pits obtained during removal of the Si layers. Triangle edges are parallel to the three $\langle 1-10\rangle$ equivalent directions. AFM observations, performed after increasing etching times revealed an increase of the average size of triangles, indicating a progressive growth.

\section{Discussion.}

The interpretation of results requires to consider the dissolution process of $\mathrm{Si}$ and the energy diagram of the contact $\mathrm{Si} /$ solution. When dipping $\mathrm{Si}(111)$ samples in $40 \% \mathrm{NH}_{4} \mathrm{~F}$, a situation also 


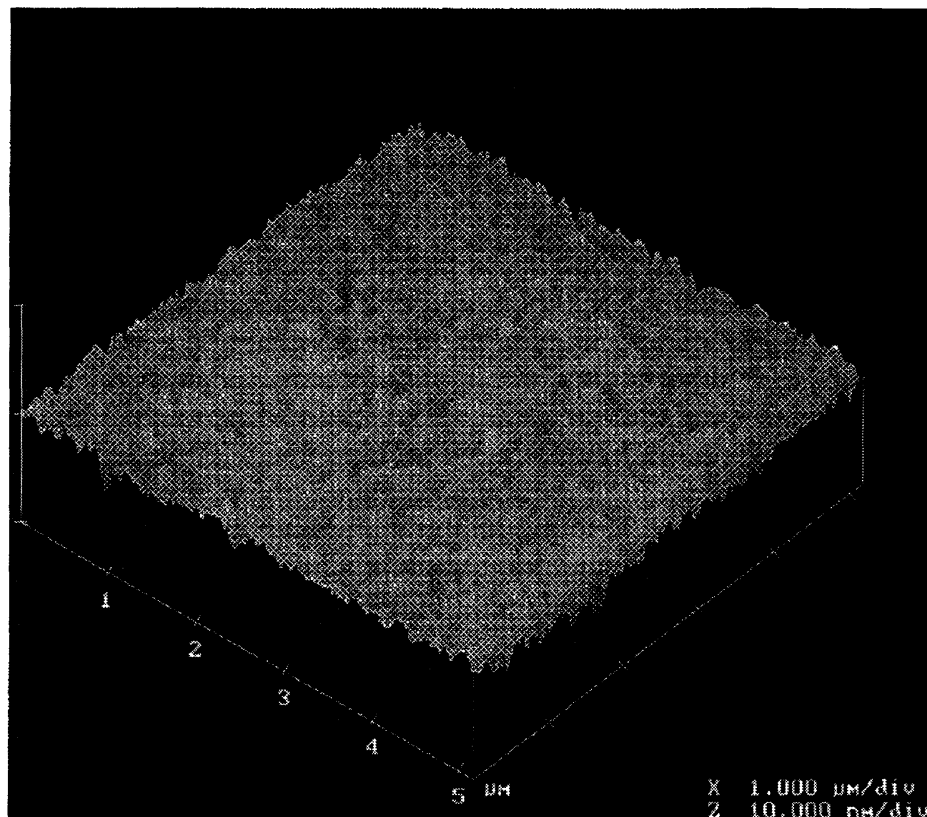

initid surface

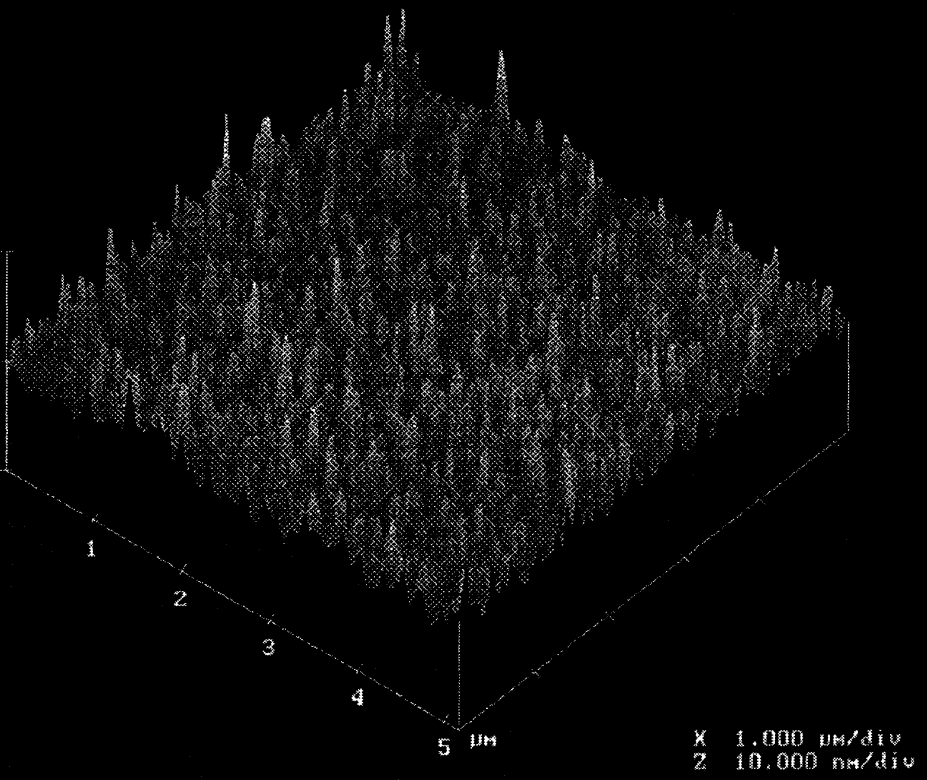

$15 \mathrm{mn}$ etching

Fig. 1. - Sequence of AFM images $(5.12 \mu \mathrm{m} \times 5.12 \mu \mathrm{m})$ revealing the progressive modifications of the initial surface after different etching times. 


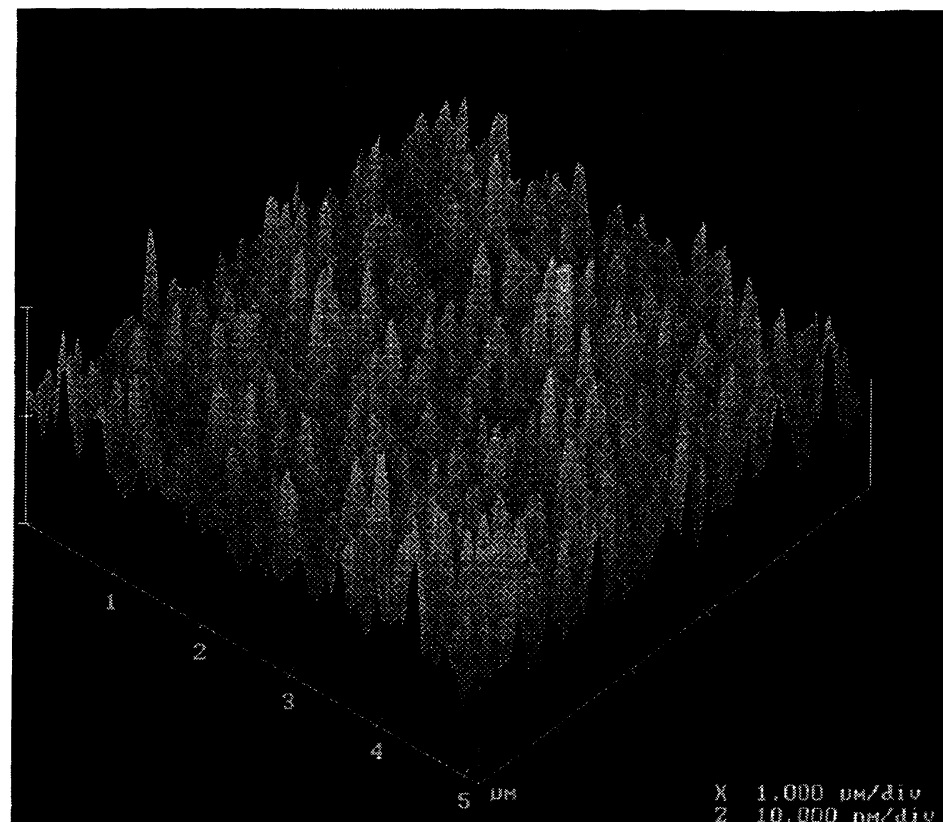

$30 \mathrm{~nm}$ etohing

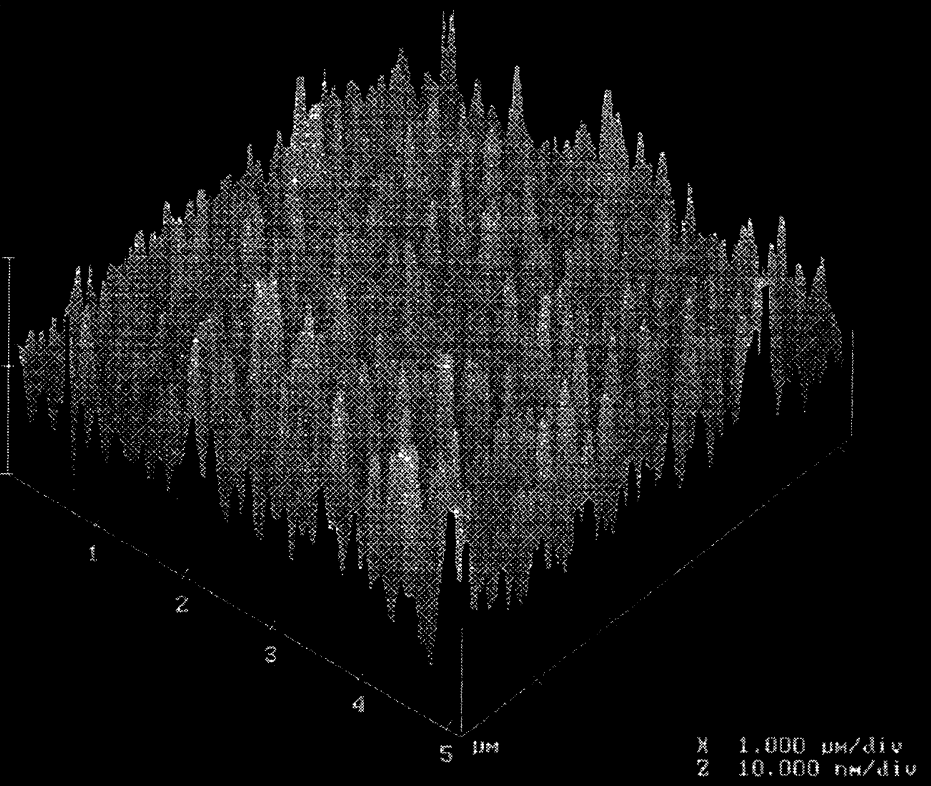

$60 \mathrm{mn}$ etching

Fig. 1. - Continued. 


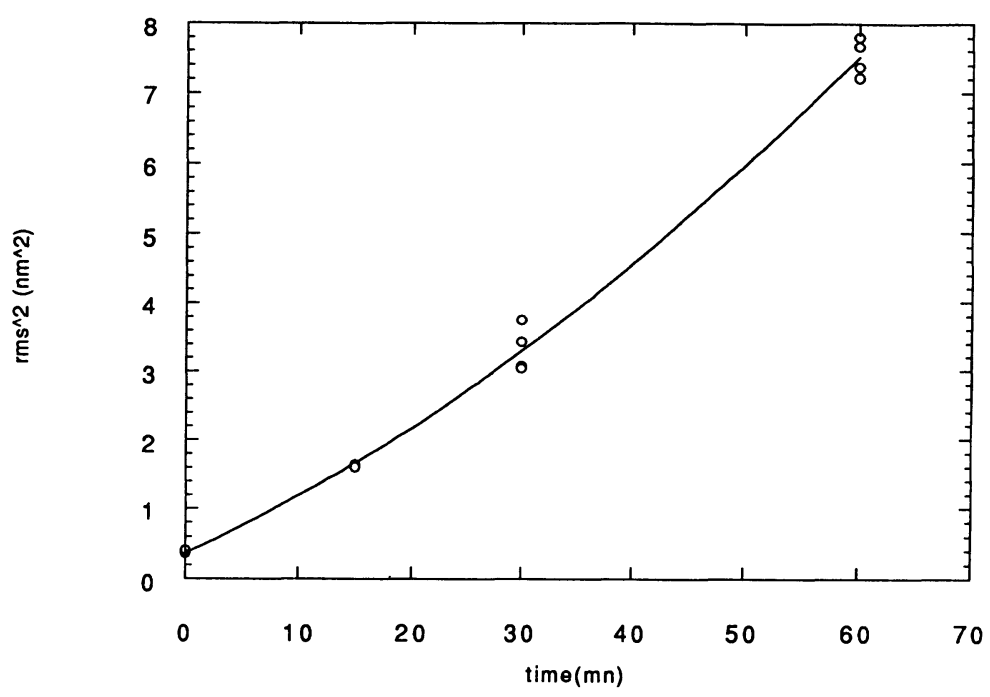

Fig. 2. - Time dependence of the rms height profile.

referred to as "chemical" etching, Si dissolves according to a chemical (CE) and an electrochemical (EC) mechanism which are running in parallel. The EC mechanism of dissolution involves free carrier transfer across the interface. This is an anodic process meaning that holes are transferred to solution from the solid or that electrons enter the solid. The "chemical" etching situation being a zero current situation, a cathodic electrochemical current equal and opposite to EC dissolution must exist (i.e. electrons must be transferred from the solid to solution).

4.1 REACTION MODEL. - In its very initial stages, the dissolution begins with the hydrolysis Si$\mathrm{H} \rightarrow \mathrm{Si}-\mathrm{OH}$ at any $\mathrm{pH}[9,13]$. This first step can be either a $\mathrm{CE}$ or an EC process as shown in figure 4. The CE hydrolysis (Fig. 4, top) occurs in a single step when a water molecule comes into close proximity of the $\mathrm{Si}-\mathrm{H}$ bond to react. $\mathrm{A} \mathrm{H}_{2}$ molecule is released during this sequence. The EC hydrolysis (Fig. 4, bottom) is a two step mechanism, including the dissociation of the Si-H bond followed by the attachment of the $\mathrm{OH}$ group on the $\mathrm{Si}^{(*)}$ sites [a $\mathrm{Si}^{(*)}$ species corresponds to charged surface states located on a $\mathrm{Si}$ atom which has lost its $\mathrm{H}$ ligand]. One proton is released and 2 electrons are thermally injected into the conduction band. For the sake of clarity the EC reaction has been equilibrated for only one substitution in figure $4 \mathrm{~b}$. The formed $\mathrm{Si}-\mathrm{OH}$ groups, which are precursors to dissolution, enable the removal of the $\mathrm{Si}$ atom from the surface as $\mathrm{HSiX}_{3}$ (with $\mathrm{X}=\mathrm{F}$ or $\mathrm{OH}$ ) after several purely chemical steps. These steps are faster than the hydrolysis process, which must be rate determining to explain the surface remains H-terminated (see Refs. $[9,13-14]$ for more details).

The primary aim of the above description was to show that atomically flat terraces on $\operatorname{Si}(111)$ are the result of chemical dissolution while rough surfaces are due to enhanced electrochemical process. The chemical hydrolysis is indeed easiest and fastest at step edge for steric reasons and also because $\mathrm{Si}-\mathrm{H}$ bonds are almost in the surface plane (Fig. 4a). The EC Si-OH bond formation is in contrast possible on terraces since the dissociation of the $\mathrm{Si}-\mathrm{H}$ bond dissociation allows reaction between molecular water and formed $\mathrm{Si}^{(*)}$ sites. This fits in-situ STM observations [4, 7, 9] and Monte-Carlo simulation of the dissolution [18] showing that the relative importance of the two reaction paths depends on several parameters such as the solution chemistry ( $\mathrm{pH}$, concentration in fluoride species, potential, etc.) [6-9] on low doped n-Si substrates. 


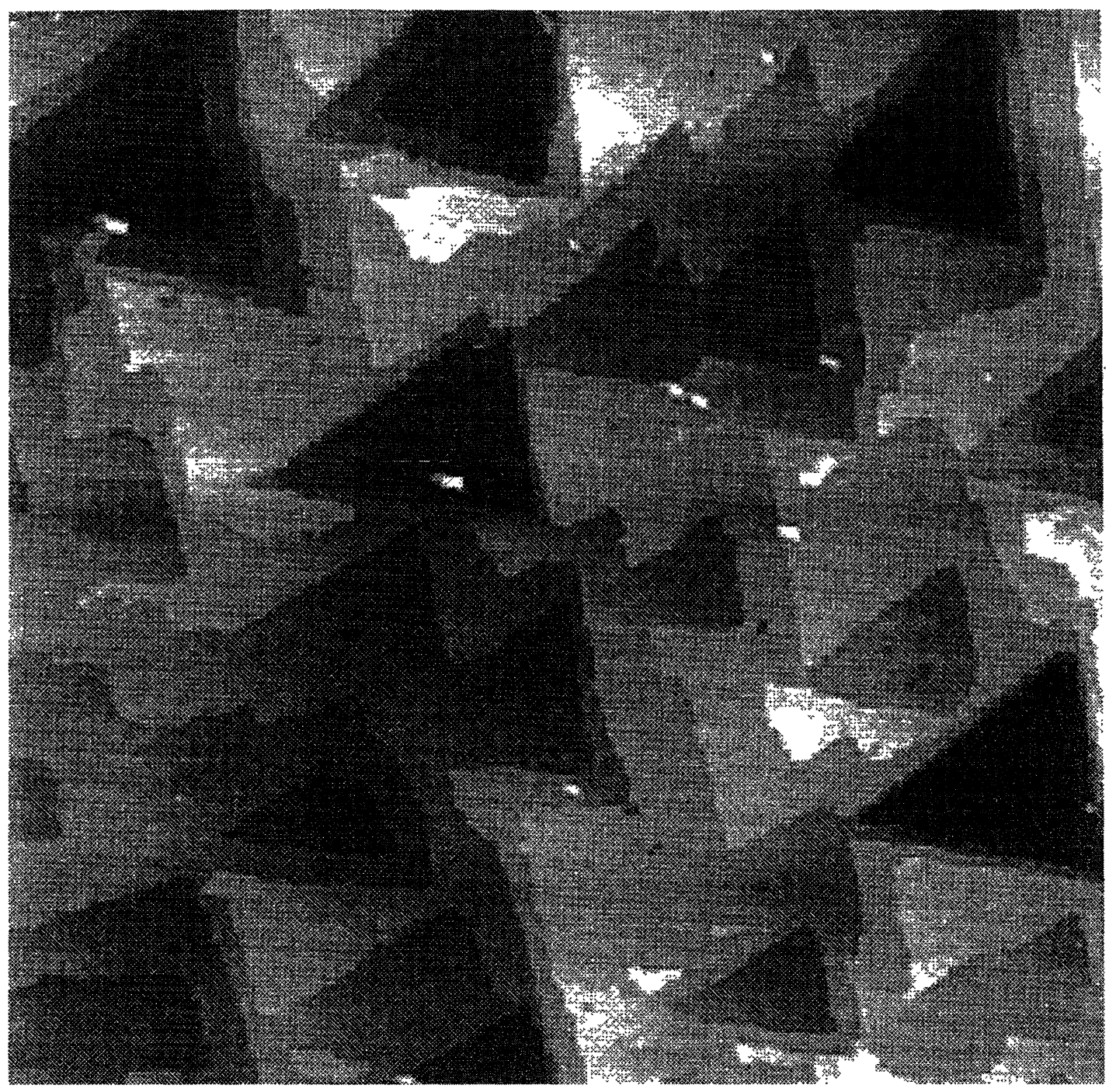

Fig. 3. - UHV-STM image of the n-type Si(111) surface after $4 \mathrm{mn}$ etching. Etch pits have a triangular shape with edges parallel to $\langle 1-1-0\rangle$ equivalent directions.

That ideally flat surfaces can be prepared in $40 \% \mathrm{NH}_{4} \mathrm{~F}$ [12] comes from the fact that the dissolution is $50 \%$ chemical in nature and from a rather small etch rate $(\sim 2 \AA / \mathrm{min}$ on low doped $\mathrm{n}$-Si(111) with a miscut of $1^{\circ}$ ) [9]. On precisely oriented samples, as in figure 3 , the dissolution proceeds according to the nucleation and growth of triangular pits (one double layer deep), whose edges, parallel to $\langle 1-10\rangle$ directions correspond to $=\mathrm{Si}-\mathrm{H}$ monohydride terminated steps which are the most stable ones. This has also been observed by others [15]. On stepped surfaces the lateral flow of steps may be faster than the nucleation of triangular etch pits leaving an almost perfect staircase arrangement of terraces $[5,15]$. The origin of the increasing roughness with increasing doping effect (Figs. 1-3) strongly suggests that the EC reaction path becomes enhanced with increasing doping. 


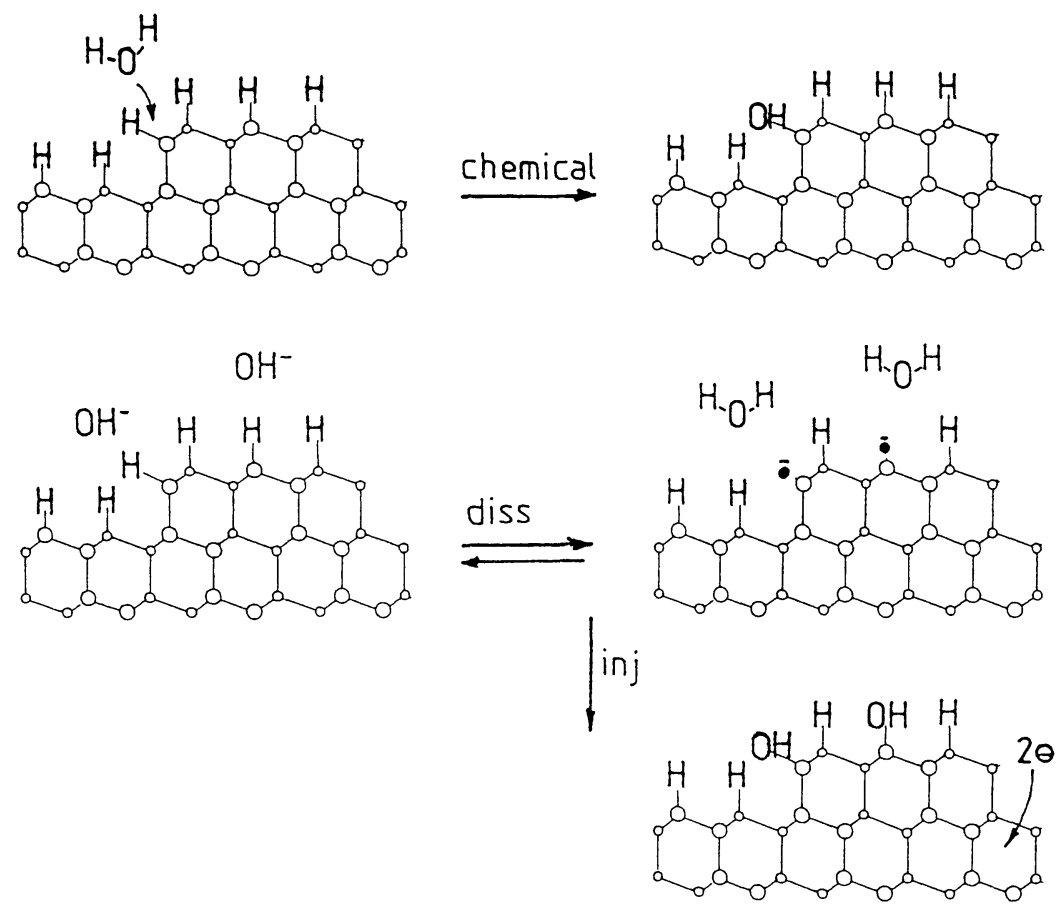

Fig. 4. - Schematic reaction models showing the formation of $\mathrm{Si}-\mathrm{OH}$ groups, which are precursor to $\mathrm{Si}$ etching (after Ref. [A11]=. Top: Chemical mechanism. Bottom: Electrochemical mechanism. The 2 electrons in excess in the second step are injected into the conduction band.

4.2 BAND MODELS OF THE INTERFACE. - Figure 5 presents two series of band diagrams showing the $\mathrm{Si}(111) / \mathrm{NH}_{4} \mathrm{~F}$ interface at the different steps of the EC hydrolysis (see Fig. 4 bottom). The position of bands with respect to solution levels and the band bending have been experimentally derived from capacitance measurements $[9,19] \ldots$ The rest potential, i.e. the Fermi level of both samples, is nearly equal to the $\mathrm{H}_{2} \mathrm{P} / \mathrm{OH}^{-}$redox potential. The position of different energy levels at the surface has been discussed previously [14]: i) Si-H related states are assumed to be close to the valence band maximum (VBM); ii) $\mathrm{Si}^{*}$ related state is considered to be located in the band gap since it roughly corresponds to a dangling bond, state $\mathrm{Si}^{(-)}$is simply state $\mathrm{Si}^{*}$ filled with a supplementary electron; iii) the "activated state" is a transient state during injection of the electrons. This is an antibonding state of $\mathrm{Si}-\mathrm{OH}$ and must be in the conduction band. Arrows are featuring the reaction steps shown below each diagram. Reactants are preceded by $(+)$ and products by $(-)$. Arrows labelled as D and I correspond respectively to the dissociation and the electron injection steps in figure 4 (bottom). Mechanism $\mathrm{E}$ is designing the thermionic emission of holes over the barrier (shown for $\mathrm{p}$-Si only). Last process $\mathrm{H}$ is the hydrogen evolution reaction and follows equation $2 \mathrm{H}_{2} \mathrm{O}+2 \mathrm{e}^{-} \rightarrow \mathrm{H}_{2}+2 \mathrm{OH}^{-}$at intermediate $\mathrm{pH}$. Note that processes $\mathrm{H}$ and $\mathrm{I}$ are not sequential, contrary to processes $\mathrm{D}$ and $\mathrm{I}$ or $\mathrm{E}$ and I.

"Chemical etching" is to a zero current situation, which means that the dissolution (forward) current must compensated by the electrochemical hydrogen evolution. For the sake of simplicity, we consider in the following a sequence for the dissolution of a single $\mathrm{Si}$ atom. At $\mathrm{n}$-Si dissolution is solely arising from mechanism $\mathrm{D}$ (whose rate is also equal to that of process $\mathrm{I}$, since $\mathrm{D}$ and $\mathrm{I}$ are sequencial). The net forward dissolution reaction is $\mathrm{Si}-\mathrm{H}+\mathrm{H}_{2} \mathrm{O} \rightarrow \mathrm{Si}-\mathrm{OH}+2 \mathrm{e}^{-}+2 \mathrm{H}^{+}$. Two electrons are injected into the conduction band and one molecule of $\mathrm{H}_{2}$ per Si dissolved is formed 


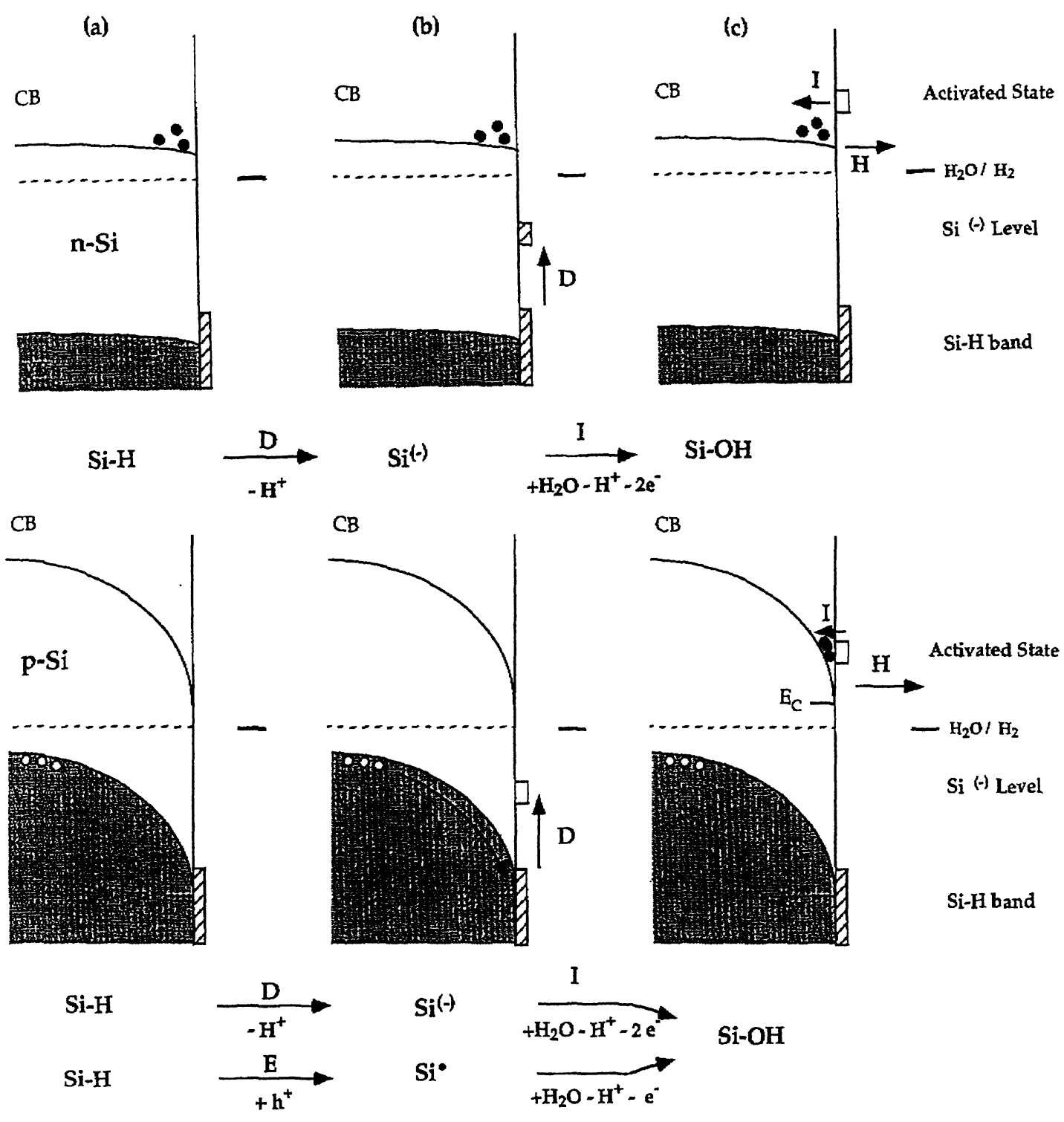

Fig. 5. - Sequences of energy diagrams showing the interfaces $\mathrm{n}$ - and $\mathrm{p}-\mathrm{Si}(111) / \mathrm{NH}_{4} \mathrm{~F}$ solution, respectively on top and bottom line, at each step of the hydrolysis step of figure 4 . See text for significance of energy levels and mechanisms labelled as D, I, E and H.

(the $\mathrm{Si}-\mathrm{OH}$ group is chemically attacked, see previous paragraph) which is consistent with known stoichiometry of Si etching $[9,14]$. At the p-Si the dissolution rate is proportional to the sum of fluxes $\mathrm{D}$ and $\mathrm{E}$. These two processes may indeed run in parallel, i.e. on different sites whereas step I necessarily follows either step $\mathrm{D}$ or step $\mathrm{E}$. The net forward reaction is therefore $\mathrm{Si}-\mathrm{H}+\mathrm{H}_{2} \mathrm{O}+$ $(1-n) \mathrm{h}^{+} \rightarrow \mathrm{Si}-\mathrm{OH}+2 \mathrm{H}^{+}+(1+n) \mathrm{e}^{-}$, with $0 \leq n \leq 1$. This equation simply expresses that the dissolution is a linear combination of the two reactions initiated by process $\mathrm{D}$ and mechanism $\mathrm{E}$ (see Fig. 5, bottom line). Whenever mechanism $\mathrm{E}$ is negligible, $n=1$ and the reaction is identical to the one given above for $\mathrm{n}-\mathrm{Si}$. In both cases the reverse reaction (process $\mathrm{H}$ ) consumes electrons 
from the conduction band which are in a sufficiently large amount at the surface either because the bands are flat at $\mathrm{n}-\mathrm{Si}$ or because the bending is nearly $1 \mathrm{~V}$ at $\mathrm{p}-\mathrm{Si}$.

Within this description, the influence of the doping level on the surface topography of p-Si depends on whether the limiting process is anodic or cathodic. In the first situation, increasing the doping level will increase the rate of hole capture by $\mathrm{Si}-\mathrm{H}$ bond (process $\mathrm{E}$ ) by tunneling into Si-H states (see Fig. 5d). The effective barrier seen by free holes in thermionic emission becomes smaller which significantly enhances the EC dissolution. In the second case, the doping level will play on bulk recombination through a decrease of the diffusion length of carriers at highly doped $\mathrm{p}-\mathrm{Si}$. The rate of the compensating EC dissolution will therefore increase and an enhanced rate of pit nucleation is expected in both situation. None of these effects is expected at $\mathrm{n}-\mathrm{Si}$.

In conclusion, it has been shown that the enhancement of the electrochemical component of dissolution under "chemical" etching condition is responsible for surface roughening observed with highly doped $\mathrm{p}$-Si samples etched in $40 \% \mathrm{NH}_{4} \mathrm{~F}$. Such an effect is not expected at n-Si with our model. Additional work is however necessary to go into more details of the mechanisms. Etch rate measurements with $\mathrm{n}$ - and $\mathrm{p}$-Si of increasing doping density as well as STM/AFM imaging is underway to complete the preliminary results presented in this paper.

\section{References}

[1] Yablanovitch E., Allara D.L., Chang C.C., Gmitter T. and Bright T.B., Phys. Rev. Lett. 57 (1986) 249.

[2] Burrows V.A., Chabal Y.J., Higashi G.S., Raghavachari K., Christman S.B., Appl. Phys. Lett. 53 (1988) 998.

[3] Venkatesware Rao A., Ozanam F. and Chazalviel J.-N., J. Electrochem. Soc. 138 (1991) 153.

[4] Rappich J., Lewerenz H.J. and Gerischer H., J. Electrochem. Soc. 141 (1994) L187.

[5] Hessel H.E., Feltz A., Memmert U. and Behm R.J., Chem. Phys. Lett. 186 (1991) 275.

[6] Allongue P., in "Advances in Electrochemical Science and Engineering", H. Gerischer and C.W. Tobias Eds., Vol. 4, Weinheim, in press.

[7] Allongue P., Kieling V. and Gerischer H., J. Electrochem. Soc. 140 (1993) 1008.

[8] Allongue P., Brune H. and Gerischer H., Surf. Sci. 275 (1992) 414-423.

[9] Allongue P., Kieling V. and Gerischer H., Electrochim. Acta, in press.

[10] Lin Yau S., Fan F.F. and Bard A.J., J. Electrochem. Soc. 139 (1992) 2825.

[11] Jakob P., Chabal Y.J., J. Chem. Phys. 95 (1991) 2897.

[12] For a review about hydrogenated Si surfaces, see G.S. Higashi and Y.J. Chabal, in "Handbook of Semiconductor Wafer Cleaning Technology", W. Kern Ed. (Noyes Publication, Park Ridge, 1993).

[13] Allongue P., Costa-Kieling V. and Gerischer H., J. Electrochem. Soc. 140 (1993) 1019.

[14] Gerischer H., Allongue P. and Costa-Kieling V., Ber. Bunsenges. Phys. Chem. 97 (1993) 753.

[15] Pietsch G.J., Köhler U. and Henzler M., J. Appl. Phys. 73 (1993) 4797 and Chem. Phys. Lett. 197 (1992) 346.

[16] Kern W., RCA Rev. 39 (1978) 278.

[17] Vatel O., Ph. D Thesis, Université de Marseille-Luminy (1993).

[18] Allongue P. and Kasparian J., Microscop. Microanal. Microstruct., this issue.

[19] Allongue P., Pinsard L., Henry de Villeneuve C. and Bernard M.C., submitted.

[20] Gerischer H. and Lübke M., Ber. Bunsenges. Phys. Chem. 91 (1987) 394. 